\title{
Desensitization Efficacy by Sublingual Immunotherapy of Shrimps Extract in Asthmatic, Rhinitis and Urticaria Allergic Patients
}

\author{
Maged M. Refaat'1, Mohammed Yousef Attia², Howida Mohamed Saber ${ }^{3}$ \\ ${ }^{1}$ Internal Medicine, Allergy and Immunology Unit, Ain-Shams University Hospital, Cairo, Egypt \\ ${ }^{2}$ Allergy and Immunology Unit, Ain-Shams University Hospital, Cairo, Egypt \\ ${ }^{3}$ Clinical Pathology Department, Faculty of Medicine, Ain-Shams University Hospital, Cairo, Egypt \\ Email: MagedRefaat@hotmail.com, mohamedyousef91@yahoo.com, \\ howida55 mohammed@yahoo.com
}

Received 14 May 2014; revised 20 June 2014; accepted 1 July 2014

Copyright $@ 2014$ by authors and Scientific Research Publishing Inc.

This work is licensed under the Creative Commons Attribution International License (CC BY).

http://creativecommons.org/licenses/by/4.0/

(c) (j) Open Access

\section{Abstract}

RATIONALE: Crustaceans, such as shrimp, crab, crayfish and lobster, play important role in human nutrition; they also can be important causes of severe acute hypersensitivity reactions. For patients diagnosed with a crustacean allergy, strict avoidance is the only proven therapy, highlighting the need for more specific treatment. Our aim was to evaluate the efficacy and tolerance of sublingual shrimp immunotherapy in Egyptian patients allergic to shrimp. METHODS: This study was intended to help in diagnosis of shrimps allergen in 60 allergic patients (subdivided to 3 groups Urticaria (G1), rhinitis (G2) \& asthma (G3)) and evaluate the sublingual immunotherapy by employing skin prick test, specific Immunoglobulin E, Total Immunoglobulin E, Immunoglobulin G, Eosinophilis and Peak Expiratory Flow Rate (PEFR), before and after therapy. Inclusion criteria were a history of shrimp allergy and positive skin prick test to crude shrimp extract from two species [Penaeus semisulcatus and Metapenaeus stebbingi] at allergy and clinical immunology unit, in-Shams Hospitals. They underwent immunotherapy with extract of shrimp species and administered sublingually (SLIT). The measurement of all latter investigations for shrimp allergen on the start and 6 months after immunotherapy, as compared to placebo control, were performed. Results: The clinical response and laboratory improvement of the patients was correlated with their decline in the eosinophils $(p<0.001)$, total Immunoglobulin $E(p<0.001)$ and specific Immunoglobulin $E$ test $(p<0.001)$ and with their increased in PEFR $(p<0.001)$ and Immunoglobulin $G(p<0.001)$. This study suggests that the most desenstized responsed group was rhinitis group followed by Urticaria group. Also,The more effective season induce allergy in summer (48.3\%) followed by springs $(28.3 \%)$ and genatic predisposition of allergic diseases was 
highly accepted in patients had a family history (68\%). In conclusion, sublingual immunotherapy for shrimp allergy was safe, simple, uncostly, well tolerated and efficacious, gave a good results especially in the treatment of patients with allergic rhinitis.

\section{Keywords}

Shrimps, Allergy, Immunotherapy

\section{Introduction}

Seafood allergy is the most common food allergy in adults and the most prevalent food allergy in young children [1]. Shrimp allergy is immunologic response to proteins in the food called tropomyosin in the Shrimp muscles and includes Immunoglobulin E antibody-mediated allergy as well as other allergic syndromes [2]. The prevalence of shrimp allergy is usually increased when the consumption plays a greater part in the diet of the observed community [3] [4]. The diagnostic workup for shrimp allergy includes clinical history, skin prick tests, measurement of specific Immunoglobulin E levels in serum and oral food challenges [4] [6].

The immunotherapy (or desensitization) involves the administration of allergen extracts in an attempt to induce immunologic tolerance and improve the treatment of allergic rhinitis, allergic asthma and urticaria hypersensitivity [7]-[10]. Our aim was to evaluate the efficacy and tolerance of sublingual shrimp immunotherapy in Egyptian patients allergic to the laboratory and clinical improvement after SLIT by employing skin test, specific Immunoglobulin E, total Immunoglobulin E, Immunoglobulin G, Eosinophilis count and Peak Expiratory Flow Rate tests. A comparative study was also done after therapy to evaluate the most highly improvement group in the treatment of shrimps allergy in Egypt.

\section{Material \& Methods}

In the present work, 60 patients were selected, suffering from shrimp allergy and another group of 20 normal control persons. Investigations were carried out at Allergy and Immunology Department, Aein-Shams Hospitals (in period from January 2009 to March 2012). The examined individuals were classified into the following groups: 60 persons divided into three groups, 28 urticarial patient (G1), 18 rhinitis patients (G2) and 14 asthmatic patient (G3) due to shrimps allergen. The patients aged from 15 to 50 years, 37 males and 23 females. 20 normal healthy persons as control (G4) aged from 16 to 40 years, 14 males and 6 females. They were free from any type of allergy or parasitic diseases.

Consents: Discussion with the patients as regards the benefits and hazards of the study was done and informed consents were provided. Approval of the Ethics Committee of Scientific Research was taken from Aein Shams Univeristy Hospitals, Faculty of medicine as the protocol followed in Allergy and Immunology Department.

\subsection{For Each Patient or Normal Subject, the Following Investigations Were Conducted}

Clinical examination and routine investigations to exclude any side disease might cause allergy: This included complete family history taking, season of attack and physical examinations by physician in the clinic. Routine investigations as Urine, stool, kidney, liver, blood sugar and X-ray chest and sinus.

Skin prick test: using shrimps extract (also for immunotherapy) skin prick method was done using shrimps extracts. All allergen extracts were prepared in Ain Shams Hospital Allergy and Immunology Extract Unit by aqueous vaccine (weigh/volume), positive (histamine) and negative (coca solution) controls were included in the prick test [11].

In our study, we used Shrimps allergen extracts which was prepared from the whole body of prawn (we extract this type because it has highly cross-reactivity with other types of shrimp [5]. We didn't notice any complications or severe reactions with shrimps extract skin testing outcomes.

Serum total Immunoglobulin E (Biochemistry chick company for kits, USA).

The Immunoglobulin E quantitative test is based on a solid phase enzyme-linked Immunosorbent Assay 
(ELISA) [12].

Specific Immunoglobulin E test for Shrimps was done for patients with positive skin prick test for Shrimps. It was done by Ala STAT Micro plate Allergen specific Immunoglobulin (RIDASCREEN Specific Immunoglobulin, Germany).

Eosinophilis Study by study blood film stained by Eosin stain and count eosinophilis cells.

Peak expiratory flow rate was measured by simplified peak flow meter [13].

Mmunoglobulin G: by radial Immune-diffusion method by plotting serum in specified wells with standard and measure the diameter of diffusion and evaluated with the reading of standard diameter (Biocientifica S.A Company).

\subsection{Immunotherapy Technique}

After fulfillment of the previous investigations for each patient. The patients had sensitivity to shrimp allergen were treated by its extract sublingually by serial dilutions.

Dilutions: 1/5000; $1 / 500$ and 1/50 (Weight/Volume). Doses: each vial 1 drop in $1^{\text {st }}$ day, 2 drops in $2^{\text {nd }}$ day, and 3 drops in $3^{\text {rd }}$ day, 4 drops in $4^{\text {th }}$ day and after those 4 drops each day until the concentration finished. Repeat the procedure in each. One or more doses were added to patients who did not give satisfactory response, from the dilution 1/50. Treatment by immunotherapy was recommended by several studies [5] [10].

\section{Results}

Results obtained up to 6 months after start of treatment achieved a significant reduction of allergic symptoms in daily life compared to placebo ( $\mathrm{p}<0.001$ ). The clinical response of the patients was correlated with a highly significant decline in specific Immunoglobulin E test $(\mathrm{p}<0.001)$ and with increased Immunoglobulin $\mathrm{G}(\mathrm{p}<$ 0.001). A subgroup analysis revealed that most responsive desensitized group was rhinitis group followed by urticaria and asthmatic group. This study suggests that the most desensitizes response group was rhinitis group followed by urticaria and asthmatic group. The more effective season induce allergy in summer (48.3\%) followed by springs (28.3\%) and gene predisposition of allergic diseases was highly accepted in patients had a family history (68\%).

Data were analyzed using the SPSS program Version 15 as follows: A p value of was chosen as the level of statistical $p$ value $>0.05$ is non-significant. $p$ value $<0.05$ is significant. $p$ value $<0.01$ is highly significant.

\section{Discussion}

As regard the total Immunoglobulin E, the results before therapy in G1, G2 and G3 respectively: 176.5, 144.2 \& 174.4 IU/ml in Table 1. This elevation of total Immunoglobulin E as a result of allergy due to extrinsic factors (shrimps allergen) which increase the concentration of allergic antibodies of total Immunoglobulin E, leading to elevate the severity of allergy [13]-[15]. The response to the treatment after therapy in the three groups by decline in means respectively: 86.9, 72.8, 92.0, the more improvement group was rhinitis group (G2), this indicates the efficacy of therapy in this group [2]. These results supported by a study that suggest the specific immunoglobulin E may be a useful tool in epidemiological studies of asthma or other allergic disorders and to detect the type of allergens [16]. The results in Table 2 showing more improvement in rhinitis group (G2) by highly reduction in specific Immunoglobulin E trending to control followed by urticaria group in accordance with a report showed that sublingual immunotherapy is a viable and useful form of immunotherapy in rhinitis and urticaria patients [17] [18].

Comparison of G1, G2 and G3 as regard to the mean of Eosinophilis count \% before sublingual immunotherapy was elevated. This might be an expected result because eosinophil was one of the soluble markers of allergic inflammation. The highly reduction of eosinophilis in the three groups after therapy as the following: 1.04, 1.22 and $0.78 \%$ in Table 3 . More reduction in asthmatic group followed by urticaria and rhinitis, the immunotherapy significantly decrease antigen induced eosinophils migration to the nasal cavity, the number of eosinophils in peripheral blood has been shown to be correlated with the severity of asthma [14]. The comparison between the patient groups regard to PEFR before and after sublingual immunotherapy in Table 4 the highly improvement in percentage in the asthmatic group [10]. 
Table 1. Comparison between G1, G2 and G3 as regard to Total IgE before and after sublingual immunotherapy.

\begin{tabular}{|c|c|c|c|c|c|c|c|c|}
\hline \multicolumn{9}{|c|}{ Total Immunoglobulin E IU/ml } \\
\hline \multirow{2}{*}{ Groups } & \multicolumn{3}{|c|}{ Before } & \multicolumn{3}{|c|}{ After } & \multicolumn{2}{|c|}{ Paired t-test } \\
\hline & Mean & \pm & SD & Mean & \pm & SD & $\mathrm{T}$ & $\mathrm{p}$ value \\
\hline Urticaria (G1) & 176.500 & \pm & 43.380 & 92.071 & \pm & 22.699 & 11.183 & $<0.001^{* *}$ \\
\hline Rhinitis (G2) & 144.222 & \pm & 42.141 & 72.833 & \pm & 21.675 & 6.347 & $<0.001^{* *}$ \\
\hline Bronchial asthma (G3) & 174.429 & \pm & 65.812 & 86.929 & \pm & 26.022 & 6.809 & $<0.001^{* *}$ \\
\hline
\end{tabular}

Table 2. Comparison between G1, G2 and G3 as regard to Specific Immunoglobulin E for shrimp allergen before and after sublingual immunotherapy.

\begin{tabular}{|c|c|c|c|c|}
\hline \multicolumn{5}{|c|}{ Specific Immunoglobulin E for shrimp allergen KU/ML } \\
\hline \multirow{2}{*}{ Groups } & Before & After & \multicolumn{2}{|c|}{ Paired t-test } \\
\hline & Mean \pm SD & Mean \pm SD & $\mathrm{T}$ & $\mathrm{p}$ value \\
\hline Urticaria (G1) & $0.889 \pm 0.238$ & $0.404 \pm 0.115$ & 13.610 & $<0.001^{* *}$ \\
\hline Rhinitis (G2) & $0.627 \pm 0.229$ & $0.334 \pm 0.054$ & 5.991 & $<0.001^{* *}$ \\
\hline Bronchial asthma (G3) & $0.856 \pm 0.325$ & $0.410 \pm 0.102$ & 6.575 & $<0.001^{* *}$ \\
\hline
\end{tabular}

Table 3. Comparison between G1, G2 and G3 as regard to eosinophil count \% before and after sublingual immunotherapy.

\begin{tabular}{ccccc}
\hline & \multicolumn{3}{c}{ Eosinophil count \% } & \\
\hline \\
Groups & Before & After & Paired t-test \\
& Mean \pm SD & Mean \pm SD & T & p value \\
Urticaria (G1) & $5.357 \pm 1.446$ & $1.036 \pm 0.693$ & 16.153 & $<0.001^{* *}$ \\
Rhinitis (G2) & $4.444 \pm 1.097$ & $1.222 \pm 0.808$ & 10.447 & $<0.001^{* *}$ \\
Bronchial asthma (G3) & $5.357 \pm 1.946$ & $0.786 \pm 0.699$ & 7.744 & $<0.001^{* *}$ \\
\hline
\end{tabular}

Comparison between patient groups as regard total Immunoglobulin G before therapy in Table 5 and after sublingual immunotherapy the highly elevated Immunoglobulin G response in the rhinitis group (G2), this mean more improvement in allergic symptoms of rhinitis patients, this result according to many authors cleared that mechanistic explanations proposed to explain its therapeutic effects include an increase in immunoglobulin $G$ activity and immunotherapy induce blocking antibodies of Immunoglobulin $\mathrm{E}$ by Immunoglobulin $\mathrm{G}$ to be responsible for the well-known effects of hyposensitivity [6] [10].

The comparison of G1, G2 and G3 as regard to skin test after sublingual immunotherapy, the negative test was remarked in G2 and mild in group G1, this confirming with other studies [4].

In Table 6, a good correlation was found between total Immunoglobulin E, specific Immunoglobulin E, peak expiratory flow rate, eosinophilis, skin test and Immunoglobulin G.

From treatment group there is considerable evidence suggesting that the Shrimps oral therapy can produce a satisfactory improvement, and serve as safely, effective and cheap method in treatment. Moreover, it induced "blocking antibodies" to be responsible for the well-known effects of hypo-sensitization. So, the anti-histaminic medication alone can't be considered a complete treatment for allergy [8] [14] [19] [20].

The more effective season induce allergy in summer (48.3\%) followed by springs (28.3\%) in Figure 1 and gene predisposition of allergic diseases was highly accepted in patients had a family history (68\%) in Figure 2. 
Table 4. Comparison between G1, G2 and G3 as regard to PEFR before and after sublingual immunotherapy.

\begin{tabular}{ccccc}
\hline & \multicolumn{2}{c}{ PEFR\% } & & \\
\hline & & & & Paired t-test \\
Groups & Before & After & T & p value \\
& Mean \pm SD & Mean \pm SD & & $>0.05$ \\
Urticaria (G1) & $83.750 \pm 4.222$ & $85.357 \pm 7.809$ & -1.180 & $<0.05^{*}$ \\
Rhinitis (G2) & $74.444 \pm 5.113$ & $79.444 \pm 6.617$ & -2.766 & $<0.001^{* *}$ \\
Bronchial asthma (G3) & $54.286 \pm 7.810$ & $81.071 \pm 9.025$ & -9.237 & \\
\hline
\end{tabular}

Table 5. Comparison between G1, G2 and G3 as regard to Total Immunoglobulin G before and after sublingual immunotherapy.

\begin{tabular}{|c|c|c|c|c|}
\hline \multicolumn{5}{|c|}{ Immunoglobulin G mg/dl. } \\
\hline \multirow{2}{*}{ Groups } & \multirow{2}{*}{$\begin{array}{c}\text { Before } \\
\text { Mean } \pm \text { SD }\end{array}$} & \multirow{2}{*}{$\begin{array}{c}\text { After } \\
\text { Mean } \pm \text { SD }\end{array}$} & \multicolumn{2}{|c|}{ Paired t-test } \\
\hline & & & $\mathrm{T}$ & p value \\
\hline Urticaria (G1) & $1034.393 \pm 190.308$ & $1698.929 \pm 291.298$ & -12.158 & $<0.001^{* *}$ \\
\hline Rhinitis (G2) & $1105.833 \pm 174.852$ & $1748.333 \pm 256.431$ & -10.908 & $<0.001^{* *}$ \\
\hline Bronchial asthma (G3) & $938.857 \pm 123.180$ & $1498.714 \pm 227.014$ & -10.530 & $<0.001^{* *}$ \\
\hline
\end{tabular}

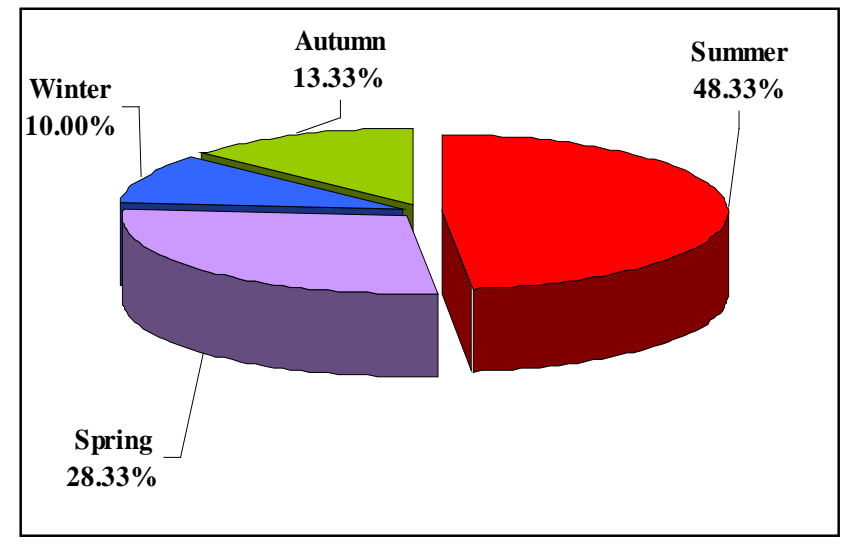

Figure 1. A pie-diagram showing percentage of seasonal duration.

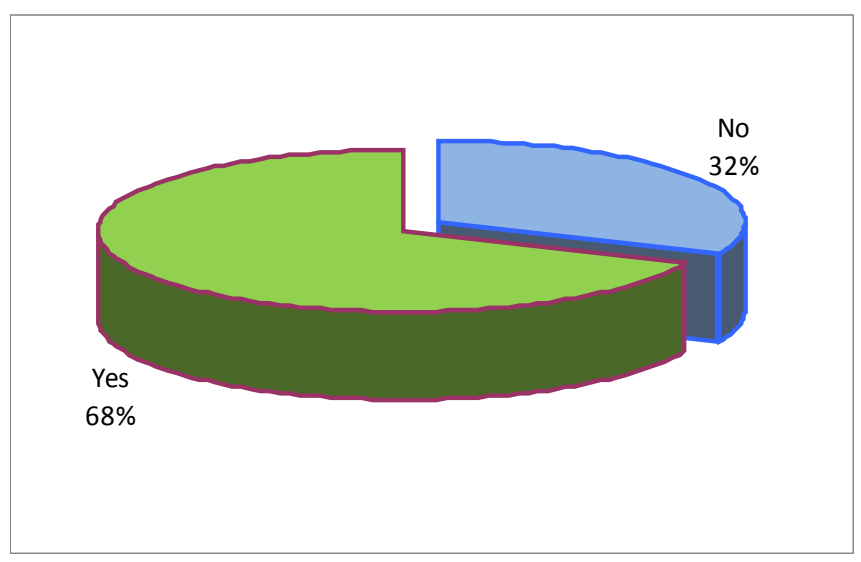

Figure 2. A pie-diagram showing family history for shrimp allergy. 
Table 6. Correlations between all variables.

\begin{tabular}{crcc}
\hline No. & Correlation group & $R$ & p value \\
\hline 1 & Total Immunoglobulin E and Total Immunoglobulin G & $>0.05$ \\
2 & Total Immunoglobulin and Eosinophil count\% & -0.034 & $<0.001^{* *}$ \\
3 & Total Immunoglobulin E and PEFR & $0.864^{* *}$ & $<0.001^{* *}$ \\
4 & T. IgE and Sp. Total Immunoglobulin E for shrimp allergen & $0.450^{* *}$ & $<0.001^{* *}$ \\
5 & Eosinophil count\% and Total Immunoglobulin G & $0.899^{* *}$ & $>0.05$ \\
6 & Eosinophil count\% and PEFR & -0.084 & $<0.001^{* *}$ \\
7 & Eosinophil count\% and Specific Immunoglobulin E for shrimp allergen & $-0.433^{* *}$ & $0.858^{* *}$ \\
9 & Total Immunoglobulin G and PEFR & 0.077 & $>0.001^{* *}$ \\
10 & Total Immunoglobulin G and Specific Immunoglobulin E for shrimp allergen & -0.064 & $>0.05$ \\
\hline
\end{tabular}

\section{Conclusion}

Shrimps sublingual immunotherapy was introduced in Egypt by its highly improvement in laboratory \& clinical manifestations in the three types of allergy included in this study, sublingual immunotherapy for shrimp allergy was safe, simple, uncostly, well tolerated and efficacious, gave a good results especially in the treatment of patients with allergic rhinitis. Precuation was intended in summer season and predisposition of allergy in patients with family history.

\section{Acknowledgements}

Conflicts of interest to Prof. Dr. Damhogy, Prof. of Zoology Department, Al-Azhar Univeristy, for his effort in collection the samples.

\section{References}

[1] Ivor, E.A., Michael, P.J. and Traub, O. (2009) Under Treatment of Allergy: Exploring the Utility of Sublingual Immunotherapy. Otolaryngology—Head and Neck Surgery, 140, 615-621. http://dx.doi.org/10.1016/j.otohns.2009.01.023

[2] Dworin, M. (1979) Use of the Pulmonary Mointor in the Control of Asthma. The American College of Allergists. 35th Annual Congress, San Francisco, 25-31.

[3] El-Shami and Aloba (1989) Liquid Phase in Vitro Allergen IgE Assay with Situimmobilization. Advanced Bio Sci., 74, 191-201.

[4] Nancy, O. (2009) Food Allergy in Children. Minnesota Physician, 13, 16-17.

[5] Leatherman, B.D., Owen, S., Parker, M., et al. (2007) Sublingual Immunotherapy: Past, Present, Paradigm for the Future? A Review of the Literature. Otolaryngology—Head and Neck Surgery, 136, S1-S20.

[6] Kelly, K.J. and Brian, K. (2010) Diagnosis and Treatment of Latex Allergy. Inernal Allergy Frontiers: Therapy and Prevention, Pawankar R. Springer Japan.

[7] Frew, A.J. (2010) Allergen Immunotherapy. Journal of Allergy \& Clinical Immunology, 125, S306-S313.

[8] Jirapongsananuruk, O., Sripramong, C., Pacharn, P., et al. (2008) Specific Allergy to Penaeus monodon (Seawater Shrimp) or Macrobrachium rosenbergii (Fresh-Water Shrimp) in Shrimp-Allergic Children. Clinical Experimental Allergy, 38, 1038-1047. http://dx.doi.org/10.1111/j.1365-2222.2008.02979.x

[9] Lopata, A.L., O’Hehir, R.E. and Lehrer, S.B. (2010) Shellfish Allergy. Clinical \& Experimental Allergy, 40.

[10] Ivor, E.A., Michael, P.J. and Traub, O. (2009) Under Treatment of Allergy: Exploring the Utility of Sublingual Immunotherapy. Otolaryngology—Head and Neck Surgery, 140, 615-621.

[11] Villalta, D., Tonutti, E., Visentini, D., Bizzaro, N., Roncarolo, D., Amato, S. and Mistrello, G. (2010) Detection of a Novel 20 kDa Shrimp Allergen Showing Cross-Reactivity to House Dust Mites. European Annals of Allergy and Clinical Immunology, 42, 20-24. 
[12] Passalacqua, G. and Canonica, G.W. (2006) Sublingual Immunotherapy. Current Opinion in Allergy \& Clinical Immunology, 6, 449-454. http://dx.doi.org/10.1097/01.all.0000246617.41871.40

[13] Hamilton, R.G. and Adkinson, N.F. (2003) Clinical Laboratory Assessment of IgE-Dependent Hypersensitivity. Journal of Allergy and Clinical Immunology, 111, S687-S701. http://dx.doi.org/10.1067/mai.2003.123

[14] Douglass, J.A. and O’Hehir, R.E. (2006) Diagnosis, Treatment and Prevention of Allergic Disease: The Basics. Medical Journal of Australia, 185, 228-233.

[15] Sicherer, S.H. and Sampson, H.A. (2010) Food Allergy. Journal of Allergy \& Clinical Immunology, 125, S116-S125.

[16] Nowak-Węgrzyn, A. and Fiocchi, A. (2010) Is Oral Immunotherapy the Cure for Food Allergies? Current Opinion in Allergy and Clinical Immunology, 10, 214-219. http://dx.doi.org/10.1097/ACI.0b013e3283399404

[17] Asero, R., Mistrello, G., Ariano, R., Colombo, G., Conte, M.E., Crivellaro, M., de Carli, M., Torre, F.D., Emiliani, F., Rizzini, F.L., Longo, R., Macchia, D., Minale, P., Murzilli, F., Nebiolo, F., Quercia, O., Senna, G.E. and Villalta, D. (2012) Shrimp Allergy in Italian Adults: A Multicenter Study Showing a High Prevalence of Sensitivity to Novel High Molecular Weight Allergens. International Archives of Allergy and Immunology, 157, 3-10. http://dx.doi.org/10.1159/000324470

[18] Bidad, K., Nicknam, M.H. and Farid, R. (2011) A Review of Allergy and Allergen Specific Immunotherapy. The Iranian Journal of Allergy, Asthma and Immunology, 10, 1-9.

[19] Straumann, A., Conus, S., Grzonka, P., et al. (2010) Anti-Interleukin-5 Antibody Treatment (Mepolizumab) in Active Eosinophilic Oesophagitis: A Randomised, Placebo-Controlled, Double-Blind Trial. Gut, 59, 21-30. http://dx.doi.org/10.1136/gut.2009.178558

[20] Slavin, R.G. and Reisman, R.E. (2001) Textbook: Expert Guide to Allergy and Immunology. Fulcrum Data Services, Philadelphia. Allergic Skin Diseases, 81-103. Rhinitis, 23-28.

\section{Units}

mg/dl: milligram per deciliter;

IU/ml: international unit per milliliter;

KU/ml: king unit per milliliter. 
Scientific Research Publishing (SCIRP) is one of the largest Open Access journal publishers. It is currently publishing more than 200 open access, online, peer-reviewed journals covering a wide range of academic disciplines. SCIRP serves the worldwide academic communities and contributes to the progress and application of science with its publication.

Other selected journals from SCIRP are listed as below. Submit your manuscript to us via either submit@scirp.org or Online Submission Portal.
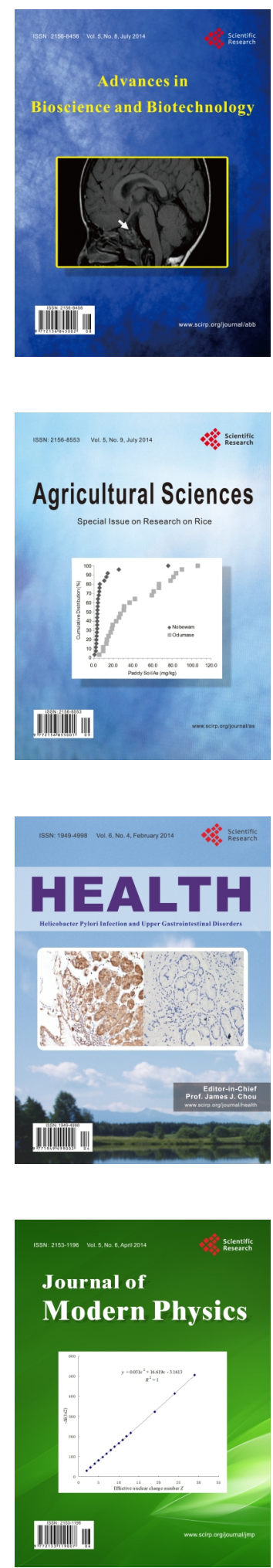
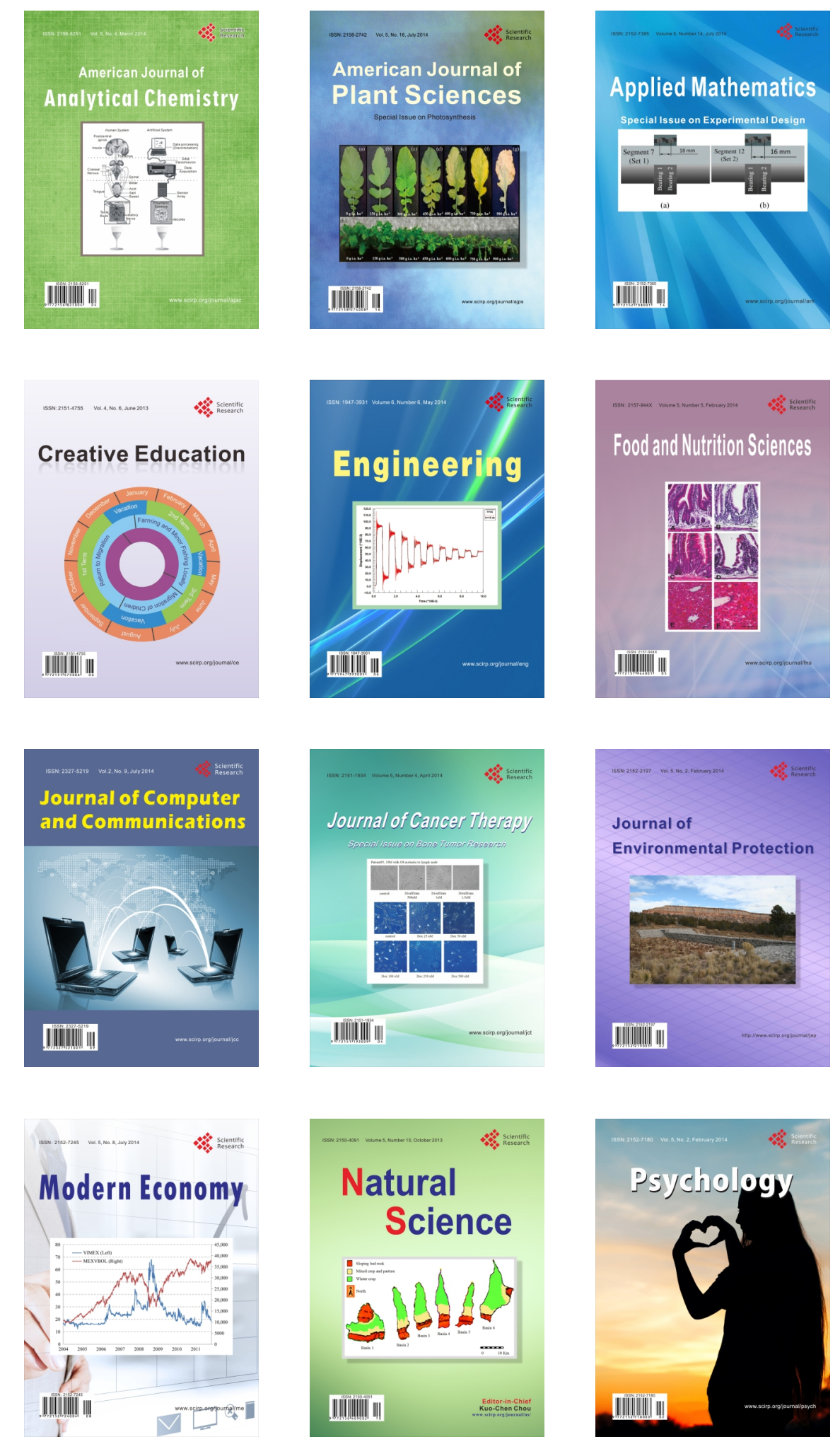